\title{
Uma leitura cognitiva do processo de perda não patológica de língua materna
}

Felipe Flores Kupske

Athany Gutierres ${ }^{b}$

\begin{abstract}
Resumo
O processo de perda não patológica de uma lingua materna, aqui tomado como atrito de L1, é um fenômeno que apenas recentemente tem sido investigado com mais afinco nos estudos linguísticos e que, aos poucos, tem sido aproximado de paradigmas e modelos teóricos que o possam acomodar. Diante dessa lacuna teórica, então, buscamos, neste trabalho, uma interpretação do atrito de L1 à luz de um paradigma teórico de cognição, mais especificamente o paradigma conexionista, aproximação ainda não feita na literatura da área. Em nossa investigação, podemos perceber que o paradigma conexionista, sensivel à dinamicidade inerente à linguagem, sobretudo pela previsão de uma representação linguística complexa e por considerar o uso efetivo da linguagem como norte para o desenvolvimento linguístico, é um modelo teórico capaz de explicar o atrito linguístico.
\end{abstract}

Palavras-chave: Desenvolvimento da Linguagem; Atrito Linguístico; Conexionismo.

Recebido em: $12 / 05 / 2018$ Aceito em: 04/07/2018

a Programa de Pós-Graduação em Língua e Cultura (PPGLinC) da Universidade Federal da Bahia (UFBA). E-mail: kupske@gmail.com.

${ }^{\mathrm{b}}$ Membro do Laboratório de Ciências da Fala (LAFALA-UFBA/CNPq). Professora da Universidade Federal da Fronteira Sul (UFFS). E-mail: athany@gmail.com. 


\section{Introdução}

De maneira geral, o desenvolvimento linguístico é visto como o processo pelo qual o homem desenvolve a capacidade de perceber e produzir a linguagem para a comunicação, aptidão que nos diferencia dos animais. Assim, esse processo sempre invocou questionamentos e especulações, principalmente no que se refere a como uma criança adquire sua língua materna (L1) - o fato de, aos três anos de idade, sermos capazes de usar produtivamente nossa L1 vem intrigando estudiosos desde a Grécia antiga. Neste sentido, Lambert (1982, p. 6) aponta que "sabemos razoavelmente bastante sobre como as pessoas aprendem línguas" em decorrência dos anos de pesquisa na área. Hoje, por exemplo, já são vários os compêndios que buscam elucidar o desenvolvimento da L1 e de segundas línguas (L2). Por outro lado, o autor complementa que "sabemos muito pouco sobre como as competências linguísticas, uma vez aprendidas, são esquecidas - seja lá o que isso possa significar precisamente" (1982, p. 6). Trazemos essas citações de Lambert, pois são essas as palavras que prefaciam a primeira coletânea de trabalhos na área da linguagem - The loss of language skills (LAMBERT; FREED, 1982) - que se inclinam, especificamente, sobre a "deterioração do sistema linguístico".

O cenário de escassez teórica levantado por Lambert (1982) tem timidamente mudado, já que, segundo De Bot (2007), há um aumento de interesse na área da perda da linguagem não patológica nas últimas duas décadas por tratar-se de um domínio que pode contribuir para o melhor entendimento dos fenômenos relacionados com a dinâmica do processamento e da competência bilíngue e multilíngue, bastante em voga em nosso mundo translinguístico e transcultural. Em outras palavras, como sinaliza Kupske (2016), hoje procuramos dados na perda linguística para tentarmos entender o processo de desenvolvimento e manutenção linguística, o que nos leva a uma revisitação de como enxergamos a linguagem humana no cérebro, agora vista como dinâmica e complexa.

Embora esse campo de investigação tenha apresentado um crescimento teórico e metodológico, para Schmid (2011), Major (2010) e Kupske (2016), algumas décadas após a publicação de Lambert e Freed (1982), ainda se sabe muito pouco, ou quase nada, acerca da perda de habilidades linguísticas, sejam elas 
de uma L1 ou de uma L2, fenômeno aqui tomado como Atrito Linguístico. Nesse prisma, conforme apontam Schmid (2010) e Kupske (2016), estudos que tentam deslindar esse processo de influência da L2 na L1, atrito de L1, ainda representam uma parcela diminuta e à margem dos estudos da área de linguagem, sobretudo no Brasil.

Ainda são poucos os trabalhos que demonstram que falantes bilíngues e multilíngues podem ter a produção e a percepção em suas L1s enviesadas pelo contato com novas línguas e em diversos níveis, já que o atrito de L1 pode militar sobre o léxico e sobre todos os níveis linguísticos, da fonologia ao discurso (e.g., FLEGE, 1987; SANCIER; FOWLER, 1997; TORIBIO et al., 2005; KUPSKE, 2017). Trata-se de um fenômeno que apenas recentemente tem sido investigado com maior profundidade, aos poucos sendo aproximado de paradigmas e modelos teóricos que o possam sustentar. Sensíveis a essa lacuna teórica, buscamos, neste trabalho, uma interpretação do fenômeno do atrito de L1 à luz de um paradigma teórico de cognição, mais especificamente o paradigma conexionista, aproximação ainda não feita na literatura da área.

O paradigma aqui defendido tem suas origens nas décadas de 1950 e 1960 juntamente com o inatismo chomskiano (CHOMSKY, 1957); porém, não obteve sucesso dadas as limitações tecnológicas da época e ao poder explanatório da teoria gerativa (KUPSKE, 2011). Esse paradigma, que busca atualmente seus fundamentos na neurociência e foi propagado pela publicação dos dois volumes Parallel Distributed Processing de Rumelhart, McClelland e do grupo de pesquisa em Processamento Distribuído Paralelo em 1986, insere-se no grupo de abordagens que procuram explicar o desenvolvimento do conhecimento humano e, consequentemente, da linguagem, em termos de representações mentais e processamento de informação, rejeitando a modularidade da linguagem e o inatismo cartesiano. E é nessa perspectiva que tentaremos ler o atrito linguístico. Para tanto, iniciamos este artigo - de cunho bibliográfico - apresentando um panorama sobre o atrito linguístico (seção 2). Damos continuidade, então, apresentando o conexionismo moderno (seção 3). Encerramos com uma discussão acerca do atrito de L1 em uma perspectiva cognitiva (seção 4) e com nossas considerações finais. 


\section{Atrito linguístico: um panorama}

Segundo Köpke e Schmid (2004), a maioria das pessoas que aprenderam uma L2 na educação básica, por exemplo, irá se considerar "atritada (falantes atritados)", isto é, falantes que apresentam uma defasagem, de alguma forma, em um sistema que outrora não apresentava tais mudanças, como já sinalizado em nossa introdução. Muito embora esse fascínio seja tão antigo quanto a própria ciência da linguagem, é apenas nas últimas décadas que vem sendo construído um saber científico sobre esse tema, ainda muito limitado, contudo (KUPSKE, 2017). Segundo Schmid (2010), a metáfora por trás do nome "atrito" não é uma das mais felizes, parcialmente pelo fato da existência de muitas conotações negativas do termo e pela suposição de que o atrito evoca, categoricamente, um certo processo de redução diante de um possível e constante "lixamento" de substâncias ou tecidos, por exemplo. Entretanto, assim como a maioria dos estudos que se debruçam nessa temática, adotamos essa nomenclatura, pois, segundo Kupske (2016), "atrito" simboliza a força resultante do contato entre dois corpos, no caso, duas línguas, que se tocam, mas não se estabilizam, havendo uma constante tendência ao movimento.

Para Kupske (2016), o atrito de L1, assim como tomado no presente trabalho, estabelece-se na comunidade científica apenas na última década. Por algum tempo antes dessa revolução na área, que tem seu início marcado em 1982, o campo da perda da linguagem estava interessado em fatores instrumentais sobre a mudança e a morte linguística em comunidades de contato linguístico, como, por exemplo, imigrantes de segunda e terceira geração, bem como minorias sociais. Esses estudos enfocavam o nível de grupo/comunidade de fala, bem como os fatores socioeconômicos que atuavam sobre as mudanças. Contudo, com o estabelecimento da pesquisa em atrito, o processo psicolinguístico na perda individual da linguagem recebe um novo foco, o uso e a proficiência individual, englobando, também, o impacto, então, de fatores pessoais, mesmo que esses estejam ligados a fatores sociais (OPITZ, 2011).

De forma geral, o atrito linguístico pode ser definido como "declínio de qualquer língua (L1, L2, ou língua outra), habilidade ou parte dela em um falante saudável" (ECKE, 2004, 
p. 322). Delimitando-nos no atrito de L1, para Schmid (2007), o atrito pode ser definido de duas formas, como um processo ou como um fenômeno. A definição de atrito como processo é, de certa forma, simples: atrito de L1 pode ser definido como a perda não patológica do falar nativo de um indivíduo (KÖPKE; SCHMID, 2004). Em outras palavras, o atrito investiga a situação na qual um falante já não consegue fazer algo que anteriormente conseguia, sendo que essa perda de proficiência não é oriunda de uma deterioração cerebral, doença ou idade/envelhecimento. Assim, para Goral (2004), mais especificamente, o atrito refere-se a perdas não relacionadas com a idade, sendo que vários estudos evidenciam que algumas habilidades linguísticas podem mudar com o avançar da idade. Segundo Goral (2004), esse tipo de perda de linguagem, que ocorre no envelhecimento saudável, já foi também descrito como atrito durante os anos 1980 e 1990, embora, hoje, o foco dos estudos em atrito seja o contexto de bilinguismo. Então, atrito, comumente, relata a perda/esquecimento de uma língua oriunda de mudanças no comportamento linguístico de um falante, por exemplo, em face a um contato escasso com a comunidade na qual a língua que sofre o processo é falada (SCHMID, 2007).

Há, classicamente, dois cenários prováveis principais para esse caso: 1) quando todo o contato com aquela língua foi interrompido, não havendo mais input linguístico ou comunicação orgânica; ou 2) quando há uma grande competição com outros sistemas linguísticos, como no caso de imigrantes residentes em países de L2 dominante. Contudo, pesquisas mais recentes, como as de Cohen (2004), Lord (2008) e Schereschewsky, Alves e Kupske (2017), apontam que falantes nativos de uma L1, altamente proficientes e com contato frequente com uma L2 (e.g., professores dessa L2) podem apresentar atrito de L1 sobretudo no que concerne à produção da fala, isto é, atritam em um contexto que contradiria o esperado.

O atrito enquanto fenômeno é um pouco mais difícil de ser definido. Primeiramente, ao entendermos o atrito como processo, devemos prever dois estágios de um falante atritado, o estágio pré-atrito (A) - no qual o falante não apresenta mudanças - e o estágio de atrito (B) - no qual há mudanças significativas - , sendo que esse ínterim entre A e B faria 
referência ao fenômeno atrito. No momento em que podemos, de fato, apontar que o estágio B é diferente de A, podemos sinalizar que o fenômeno de atrito de L1 se estabeleceu. No intervalo entre os estágios A e B, há o que Schmid (2010) aponta como sintomas de atrito, isto é, o falante de uma dada L1 em um contexto de L2 dominante, por exemplo, pode apresentar uma alta variabilidade nos seus dados de produção da fala em um espectro entre aquilo que originalmente era esperado para esse falante (características de/para o uso da L1) e aquilo que será considerado não característico (uma produção da L1 com características da L2).

Já para Major (2010), o atrito de L1 pode ser definido como qualquer mudança na produção e/ou percepção que não caracteriza falantes típicos de uma mesma língua ou dialeto ou que não ocorre com esses falantes. Para Schmid (2010), atrito de L1 se aplica quando um bilíngue alcança um elevado nível de proficiência em uma L2 por utilizá-la com grande frequência e regularidade e, como consequência, apresenta uma maior variabilidade na forma da L1, agora com propriedades lexicais, gramaticais ou fonéticas próximas da L2. Segundo Cook (2006), esse fenômeno pode acontecer em diversos níveis, desde pequenas modificações, por exemplo, em nível de produção fonética, até a perda temporária ou permanente da L1, sendo esse um processo mais evidenciado em falantes que migraram para países nos quais uma L2 é dominante (KÖPKE, SCHMID, 2004).

Neste trabalho, então, adotamos o atrito de L1 como a perda estrutural não patológica e não relacionada ao envelhecimento saudável da L1 de um indivíduo. Aqui, também é importante ressaltar a diferença entre perda da língua em um indivíduo e a perda social de uma língua (DE BOT, 2007), sendo que a última acontece quando poucos ou nenhum falante resta de uma língua particular em uma população que um dia a falou. Para Crystal (2005), em casos extremos, uma língua morre quando ninguém mais a fala.

Para exemplificarmos o atrito de L1, trazemos os dados de Kupske (2016). O autor, com um desenho transversal, explorou a produção de oclusivas surdas $(/ \mathrm{p}, \mathrm{t}, \mathrm{k} /)$ em início de palavra de 32 participantes (idades entre 18 e 40 anos), grupo composto por imigrantes sul-brasileiros residentes em Londres durante períodos de tempo variados (chegada ao Reino Unido com 
idade $>18$ anos); monolíngues do inglês londrino (Standard Southern British English - SSBE); e monolíngues do português brasileiro (BP). Os alvos do PB e do SSBE /p/, /t/ e / $/$ foram apresentados nas frases-veículo "Eu diria " e "I would

say____, respectivamente, e foram gravados aleatoriamente três vezes por cada participantes. De modo geral, o estudo de Kupske (2016) revelou que imigrantes brasileiros de primeira geração residentes em Londres por mais de oito anos apresentaram diferenças estatísticas na produção de todas oclusivas surdas para o PB em relação aos seus compatriotas monolíngues. Esses imigrantes, por exemplo, apresentaram, para a produção das oclusivas do $\mathrm{PB}$, valores de Voice Onset Time (VOT) $)^{1}$ muito elevados, diferentes dos valores esperados para falantes dessa língua $(p<0,001$, com elevada magnitude de efeito). Esses resultados fornecem evidências para o atrito de L1 enfrentado pelos falantes nativos do PB (short-lag VOT) imersos em uma comunidade de L2 dominante (long-lag VOT). Em muitos dos casos, na pesquisa, os imigrantes apresentam uma duração para a oclusiva para a L1 com um valor intermediário entre o esperado para o PB-L1 e para o SSBE-L2. Posto de outra forma, brasileiros gaúchos em Londres perderam as características acústicas das oclusivas surdas da L1.

\section{O conexionismo moderno}

Embora a popularidade das pesquisas conexionistas também tenha crescido consideravelmente nas últimas duas décadas, esse paradigma não é recente. Aristóteles (400 a.C.) tem sido citado, segundo Medler (1998), como o primeiro filósofo a propor alguns dos conceitos básicos do conexionismo; como, por exemplo, que a memória é composta de elementos simples ligados ou conectados uns aos outros através de um número de mecanismos diferentes (como a sucessão temporal, similaridade entre objetos e proximidade espacial). Tais

${ }^{1} \mathrm{O}$ termo Voice Onset Time, grosso modo, faz referência ao tempo entre a soltura da oclusão e o início do vozeamento, sendo geralmente utilizado na produção e descrição das consoantes oclusivas. Maiores detalhes serão dados em seção específica estruturas associadas poderiam se combinar em estruturas complexas para trabalhos de memória.

Podemos traçar, então, uma base filosófica para o paradigma conexionista. Muitas das suposições desse paradigma advêm da Escola Materialista (e.g., LA MATTRIE, HOBBES) e são produtos do Empiricismo Britânico (e.g., BERKELEY, LOCKE, HUME). Aquela contemplava a visão de 
que nada existe, a não ser a matéria e a energia. Assim, todo comportamento humano - até mesmo o pensamento consciente - poderia ser explicado como sendo oriundo dos processos físicos do corpo humano, principalmente do cérebro. Isso serve de insumo para que os empiricistas vejam o conhecimento humano como derivado das experiências sensórias, e seria a associação dessas experiências que nos levaria ao pensamento e, consequentemente, à linguagem/comunicação. Nesta luz, segundo Finger (2008), em oposição aos racionalistas, que tradicionalmente postulam que conhecer uma língua é conhecer uma gramática, pregando que a aquisição do conhecimento somente se dá em razão do princípios inatos que os falantes possuem, os conexionistas afirmam que, "embora possamos supor que os indivíduos possuem capacidades inatas responsáveis por restringir a aprendizagem da linguagem, é de se questionar se tais capacidades incluem qualquer tipo de conhecimento prévio de estruturas gramaticais de fato (FINGER, 2008, p. 148-149).

O conexionismo moderno, após 1986, segundo Poersch (2005, p. 445), "é um paradigma cognitivo baseado nos achados da neurociência e não em hipóteses explicativas" como em um paradigma racionalista ou simbolismo (e.g., gerativismo), que hipotetiza a existência da mente para explicar os processos cognitivos. Para o conexionismo, todos os processos cognitivos ocorrem no nível cerebral e não no mental, que, segundo esse paradigma, não passa de um conjunto de processos cognitivos. Ainda para Poersch $(2007$, p. 1), "o paradigma conexionista apresenta um forte impacto no campo da cognição porque oferece respostas alternativas a velhas questões e encontra soluções para problemas ainda não resolvidos", como neste próprio trabalho, no qual tentamos explicar o atrito à luz da cognição humana.

No paradigma simbólico - racionalista -, há a postulação de um nível simbólico de representação; existem, na mente humana, estados representacionais - símbolos - que possuem estrutura combinatória. Assim, o processamento cognitivo da linguagem não passa de um processamento complexo dessas estruturas de símbolos, com base em regras, processos ou restrições. Assim, é essencial o apelo à existência de regras/ restrições, por exemplo, que determinam a combinação de estruturas e/ou produção de estruturas novas, dado o viés 
cartesiano adotado para a representação linguística, oferecendo suporte a uma perspectiva serial do conhecimento humano. $\mathrm{O}$ conexionismo, por outro lado, segundo Castro (2007), assume que o processamento ocorre em paralelo e a informação é armazenada de modo fragmentado em uma rede neuronal. “O cérebro não armazena informações por meio de símbolos, mas através de padrões específicos de atividade elétrica, que ocorrem nas sinapses interneuronais de uma rede de neurônios" (CASTRO, 2007, p. 24).

Para Finger (2008, p. 152), muitos

alegam insatisfação com a concepção simbólica, pois, segundo eles, apesar do forte apelo de recorrer-se a símbolos, regras e processos, ao reduzir todo conhecimento humano a regras, os sistemas simbólicos tornam-se frágeis e muito inflexíveis para modelar toda a capacidade cognitiva humana. Alegam que estudos rigorosos têm demonstrado que o cérebro humano possui um alto grau de flexibilidade no tratamento da informação, além da capacidade de preencher lacunas quando necessário.

Um desses exemplos de plasticidade é exatamente o fato de uma L1 não ser rígida, conforme indicam os dados das pesquisas em atrito linguístico, como de Kupske (2016), anteriormente descrito. Seus resultados sinalizam que nem mesmo gramáticas adultas são engessadas - corroborando Flege $(1995,2002)$, que aponta que os mecanismos e processos aplicados ao desenvolvimento da L1, incluindo a formação de categorias, por exemplo, mantêm-se intactos durante toda a vida de um indivíduo, aplicando-se não apenas ao desenvolvimento de L2. Corroboram, também, Best e Tyler (2007), que declaram que falantes continuam refinando, continuamente, suas percepções dos sons da fala, incluindo os de suas próprias L1s. Assim, os dados de falantes atritados podem representam um problema para modelos linguísticos simbólicos que primam pela rigidez da L1, por exemplo.

Para Poersch (2005), segundo o paradigma conexionista, o conhecimento, seja ele linguístico seja enciclopédico, é reduzido a alterações na força das sinapses neuronais e a forma como a informação é engramada na memória se dá em formas de traços atômicos distribuídos e processados em paralelo nas unidades neuronais, conectadas entre si, formando redes tridimensionais. Assim, segundo Bonilha (2004, p. 32), para 
o conexionismo, temos como unidades inatas os neurônios, unidades físicas e não mais abstratas. Esses se ligarão a outros neurônios, construindo trilhas de engramação. $\mathrm{O}$ cérebro é, então, um aglomerado de bilhões de neurônios que, ligados paralelamente, constituem redes (POERSCH, 2005). $\mathrm{O}$ neurônio, por sua vez, é constituído de uma massa central e de dois tipos de filamentos responsáveis pela formação das redes: os axônios, transmissores de eletricidade, e dendritos, receptores de impulsos elétricos (POERSCH, 2005). No ponto de encontro entre os axônios e dendritos, há o processamento de reações químicas denominadas sinapses, reações responsáveis pelo aprendizado, onde aprender significa alterar forças das sinapses (YOUNG; CONCAR, 1992 citado em POERSCH, 2005).

A Fig. 1 - retirada de Borges et al. (2015) - apresenta a estrutura dos neurônios e a representação de uma sinapse.

Figura 1 - Propagação do Impulso Nervoso

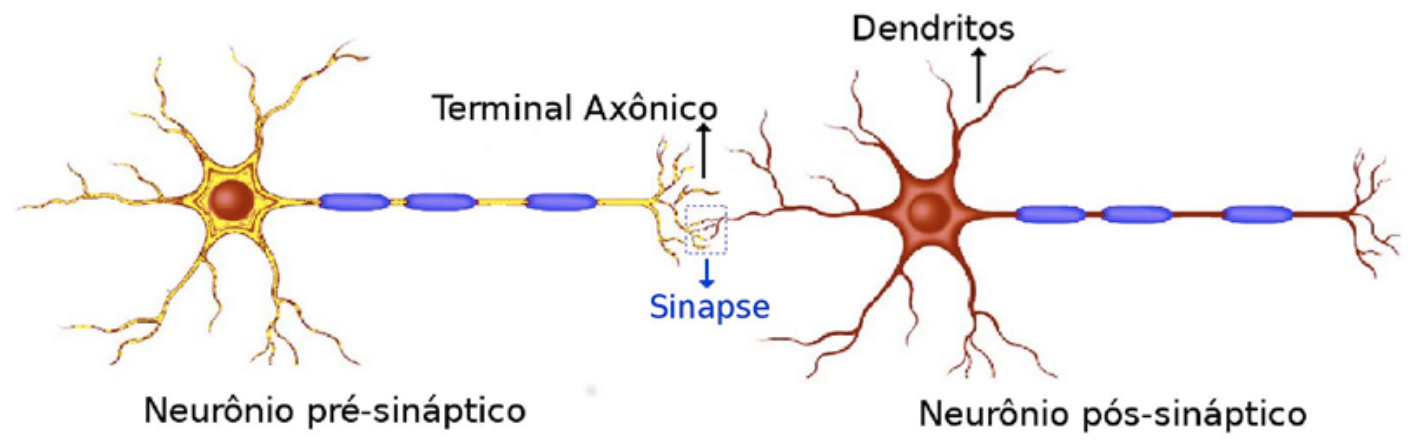

Propagação do impulso nervoso

Fonte: BORGER et al., 2015

Segundo Bonilha (2004, p. 32), a ativação entre os neurônios ocorre em graus diferenciados, assim, "cada mapeamento é distinto do outro não apenas pelas diferentes unidades que são interligadas, mas pelas diferentes forças de ligação entre as unidades envolvidas na engramação estabelecida". Ainda conforme a autora, devemos ressaltar que essas forças de ativação entre as unidades também ativarão ou desativarão outras unidades, aumentando ou diminuindo a rede de 
engramação. Um dos aspectos característicos do conexionismo é exatamente essa capacidade de processamento distribuído em paralelo, no qual um estímulo pode ativar vários neurônios simultaneamente distribuídos no corpo cerebral. Além de não haver um locus específico para um conceito, ao contrário dos módulos simbólicos, esse está em constante formação, pois pode mudar conforme a experiência humana.

\section{Aquisição, atrito e cognição}

A ontogenia do desenvolvimento linguístico tem sido muito debatida nas últimas décadas. Hoje, segundo Lizardi (2000) e Kupske (2011), abordagens conexionistas têm sido usadas nos estudos em aquisição da linguagem para corroborar os achados da neurociência. O conexionismo estuda o conhecimento humano em uma perspectiva computacional, isto é, tenta descrever o processamento cognitivo à semelhança de um computador - os dados que alimentam a rede (input), seu processamento (dados ocultos) e o output. O paradigma prevê, então, que o desenvolvimento da linguagem é uma consequência da criação de conexões repetidas de redes neuronais e se caracteriza por mudanças nos padrões dessas conexões. Para Gasser (1990), na abordagem conexionista, o conhecimento é incorporado a uma rede de unidades de processamento simples por meio de conexões que são fortalecidas ou enfraquecidas em resposta aos padrões de input oriundos da experiência linguística. Assim, além de prever o desenvolvimento da linguagem por meio da criação e fortalecimento de redes neuronais, o conexionismo prevê, também, o enfraquecimento dessas redes. Isso pode explicar, por exemplo, o atrito de L1 em imigrantes em contexto de L2 dominante, como na pesquisa de Kupske (2016). Imigrantes, por terem menos acesso às suas L1s e dada uma maior frequência de uso de suas L2s, acabam apresentando uma robustez das redes neuronais das $\mathrm{L} 2 \mathrm{~s}$ e, ao mesmo tempo, um enfraquecimento das redes para as L1s, levando ao atrito das últimas. Assim, espera-se que, quando as redes neuronais estabelecidas para a L2 tornam-se mais robustas do que as redes utilizadas para a L1, a produção dessa L1 de um falante bilíngue flutuará em direção ao padrão da L2. Em outras 
palavras, a produção da L1 apresentará características da L2, por possuir redes neuronais mais fortes.

Para Finger (2008), os conexionistas, além de defenderem que a aprendizagem é balizada pela demanda do ambiente, propõem uma nova forma de inatismo: embora admitam a postulação de uma estrutura cerebral inata responsável pelo desenvolvimento do conhecimento (o cérebro), questionam se essa é constituída de módulos especializados de acordo com o tipo de input a ser processado ou se incluem qualquer tipo de conhecimento a priori específico da linguagem. Novamente, o atrito de L1 é um dos fenômenos que nos leva a hipotetizar não haver conhecimento linguístico inato - dada a redução de habilidades linguísticas ou ao esquecimento/perda de uma L1 - mas não haver, sim, uma habilidade inata e adaptativa de se lidar com a linguagem, isto é, de retirarem-se todos os padrões linguísticos necessários para o desenvolvimento da linguagem do ambiente através do uso.

O modelo conexionista vê o desenvolvimento da linguagem sem a noção de regras simbólicas. Rumelhart e McClelland (1986) esclarecem que o desempenho linguístico é caracterizado por regras, mas essas não precisam, necessariamente, estar explícitas no mecanismo de aquisição (cérebro), ou seja, as regras são uma generalização a partir da realidade linguística orgânica de um falante, mas o desenvolvimento não se dá, obrigatoriamente, através delas. Como não há regras formais a serem aprendidas, o processamento e o desenvolvimento da linguagem ocorrem por meio do (re)ajuste gradual de conexões feitas entre os nós na recepção de inputs e produção de outputs. Novamente, são esses ajustes, balizados pelo ambiente, que podem levar um falante a atritar sua L1.

Gasser (1990) aponta que desenvolver uma língua é processar padrões, sendo que um padrão inclui características de todos os tipos que possam ser generalizadas por um falante (e.g., padrões linguísticos, acústicos e variáveis sociais que envolvem o uso desses padrões), tanto características linguísticas quanto características do próprio contexto de produção. O conhecimento de uma língua constitui-se, então, por meio de generalizações feitas através dos Complexos de Padrões Linguísticos (LPC - Linguistic Pattern Complexes), cada um sendo constituído de padrões de forma (morfossintática, 
fonológica etc.) e de conteúdo (semântico, pragmático e contextual). Para Gasser (1990), na implementação conexionista, os LPCs aparecem como padrões de ativação sobre um conjunto de unidades de input/output. Ainda segundo o autor, associações entre forma e conteúdo que compõem as LPCs são mediadas por uma camada composta por unidades complexas ocultas que compreendem o léxico/gramática de um sistema. Assim, padrões de ativação dessas unidades correspondem a inputs lexicais, bem como estruturas sintáticas. A representação é distribuída; isto é, não se pode isolar apenas uma unidade ou um conjunto de unidades que representem de forma confiável noções como oração, sujeito, onset inicial complexo ou o significado da uma palavra qualquer.

Assim, o desenvolvimento da linguagem é um processo autoassociativo. O sistema é alimentado com LCPs parciais ou complexos e, com essa base, associações são construídas por meio das características dessas estruturas. Zimmer e Alves (2005) apontam que o desenvolvimento da linguagem se dá por meio da extração das regularidades com base em fatores estatísticos e probabilísticos presentes no próprio input a que o falante é exposto, o que explica, mais uma vez, a possibilidade teórica para o atrito de L1. O desenvolvimento linguístico, para Poersch (2005), realiza-se por meio de respostas fornecidas a três tipos de estímulos: estímulos externos primários, estímulos externos secundários e estímulos internos. No caso do desenvolvimento de uma L1, os primeiros são os dados que a criança coleta em sua comunidade de fala. Tais dados são ofertados pelos falantes proficientes que serão engramados no cérebro na criança, "segundo condicionamentos probabilísticos por um lado, e de outro, por constrangimentos motivacionais, afetivos, emocionais" (POERSCH, 2007, p. 14). Já os estímulos externos secundários correspondem aos dados sobre a língua, obtidos de fontes secundárias orais ou gráficas, primando a língua como objeto de análise, e não como desempenho. O último grupo de estímulos, os internos, é oriundo do processamento interneuronal e constituem unidades intermediárias.

Como aponta Bonilha (2004), para que uma criança aprenda um conceito - embora em constante formação - como o de boneca, é necessário que ela entre em contato algumas vezes com esse objeto. A cada contato/experiência/uso, as 
engramações vão sendo feitas, reforçando ou inibindo as redes neuronais em jogo para tal conceito. "No início, pode ser apenas uma determinada boneca que a mãe lhe mostrou, no entanto, com o aumento das experiências, outros traços vão sendo mapeados. Aprender, no modelo conexionista, significa, basicamente, alterar forças das sinapses" (BONILHA, 2004, p. 33). Sabe-se, por conseguinte, que o cérebro altera sinapses para adquirir conhecimento novo. Contudo, além de reforçar sinapses, o uso (ou a falta de uso) de estruturas linguísticas provoca reajustes nas redes neuronais já existentes, e é por isso que o intenso contato como uma $\mathrm{L} 2$, mesmo residindo em países de L1 dominante, como nos casos propostos por Cohen (2004) e Schereschewsky, Alves e Kupske (2017), também pode levar ao atrito de L1. Os neurônios regulam as forças de suas sinapses durante o processamento de informação. Dessa forma, tanto o desenvolvimento quanto o atrito do conhecimento linguístico estão relacionados com mudanças sutis nas conexões neuronais (sinapses) (KUPSKE, 2011, 2016). Quando o cérebro se depara com um input, ele produz um output, e esse, por sua vez, é comparado com um alvo (produção esperada, por exemplo), que é a forma real (gramaticalmente correta) daquela palavra. A diferença entre a forma produzida pelas primeiras redes neuronais e a forma esperada é calculada para cada resultado alcançado e, através de ajustes graduais na rede, o sistema/cérebro vai aprendendo a fornecer as formas mais próximas/adequadas para as palavras apresentadas. Por isso, conforme Alves (2007), o desenvolvimento da linguagem, para o conexionismo, é lento e incremental.

É de forma não linear que o processo de desenvolvimento decorre, abrindo a possibilidade, como já vimos, para a degradação de conhecimentos já adquiridos (desde que emergentes em baixa ou nenhuma frequência), como em contextos de imigração para países de L2 dominante. Ainda para Alves (2007), no que concerne ao desenvolvimento da fonologia, devemos repensar a natureza do input linguístico. Em uma perspectiva conexionista, é o input que carrega as regularidades (linguísticas e não linguísticas) que serão estocadas probabilisticamente pelo falante. Assim, nesse prisma, o input passa a ser rico, isto é, permeado de informações linguísticas e extralinguísticas. Exemplo do impacto do extralinguístico no desenvolvimento e no atrito é o sinalizado 
por Schmid (2004) e Opitz (2011). A pesquisa de Schmid (2004) revela que alemães que imigraram como refugiados nos Estados Unidos durante a Segunda Guerra Mundial apresentam atrito do alemão-L1 e uma produção quase nativa para o inglês-L2. Ao investigar os casos de atrito de L1, há forte correlação entre memória emotiva e perda/manutenção da L1, por exemplo. Além disso, para Opitz (2011) e Kupske (2017), os valores e as atitudes diante das L1 e L2 também são decisivos no processo de perda ou manutenção da linguagem. Em outras palavras, para os autores, aqueles que possuem atitudes e valores negativos em relação às suas L1s são mais suscetíveis ao atrito, por exemplo. Assim, percebemos o efeito de variáveis extralinguísticas no desenvolvimento da linguagem. $\mathrm{Na}$ verdade, em uma perspectiva conexionista, o próprio termo extralinguístico deveria ser revisitado, já que essa sorte de variável possui, efetivamente, efeitos na linguagem humana, que, às vezes, se sobrepõe a variáveis ditas linguísticas, ao menos no que concerne ao atrito de L1 (KUPSKE, 2016).

Segundo Bonilha (2004), em uma concepção emergentista para o desenvolvimento da linguagem, dispensa-se a noção de fonema enquanto unidade abstrata. Dessa forma, o output de um falante passa ser considerado como um próprio insumo de aprendizagem. O input não é uma estrutura randomizada da subjacência, mas um ato psicofísico da superfície. O input é tanto o ponto de partida como o ponto de chegada no processo aquisicional (ZIMMER; ALVES, 2005), mas esse é, como podemos perceber, balizado pelo uso e pelo contexto de uso da linguagem. Assim, o atrito de L1 pode ser explicado pela baixa frequência do uso das línguas maternas dos imigrantes, por exemplo, como no caso de Kupske (2016). Pode ser explicado, também, pela recência e alta frequência da $\mathrm{L} 2 \mathrm{em}$ casos de atrito de L1 mesmo em contextos de L1 dominante, como nos casos levantados por Cohen (2004), Lord (2008) e Schereschewsky, Alves e Kupske (2017).

Concluímos esta seção com uma das questões que muito têm sido debatidas na área: atrito na língua adulta representa uma perda efetiva ou uma inacessibilidade do conhecimento da L1? O conexionismo, como podemos perceber, ajuda-nos a elucidar essa questão. Uma L1, para o paradigma aqui advogado, nunca é efetivamente perdida, mas torna-se mais difícil de ser acessada perante a robustez neuronal da L2, que, 
dada sua frequência, em alguns contextos, por exemplo, tornase mais forte do que a própria L1, fazendo com que a produção nessa L1 tenha características das redes neuronais da L2, agora mais fortes. Reiterando essa hipótese, estudos como o de Footnick, Pallier e Prieur (2005) revelam que falantes atritados com produção distinta do esperado para suas L1s - conseguem resgatar a fluência nativa de suas línguas durante sessões de hipnose, ressaltando que o conhecimento não se perde. Podemos pensar, então, em face do exposto, que o paradigma conexionista é capaz de acomodar o fenômeno do atrito de L1, prevendo que a perda não patológica da linguagem, em uma perspectiva cognitiva, na verdade, representa uma questão de acesso à L1 dada a forte configuração das redes da L2 e não, efetivamente, a erosão de um conhecimento já adquirido.

\section{Considerações finais}

Neste trabalho, tentamos aproximar o esquecimento não patológico de L1 ao paradigma conexionista, na tentativa de popularizar essa área de pesquisa ainda à margem dos estudos linguísticos, bem como propor uma possível explicação cognitiva para tal. No paradigma aqui advogado, o conhecimento, seja ele linguístico seja enciclopédico, é reduzido a alterações na força das sinapses neuronais, responsáveis pelo desenvolvimento, no qual aprender significa alterar forças dessas sinapses. $\mathrm{O}$ conhecimento é, assim, incorporado a uma rede de unidades de processamento simples por meio de conexões que são fortalecidas ou enfraquecidas em resposta aos padrões de input oriundos da experiência linguística, o que explicaria o processo de atrito linguístico. Como o desenvolvimento e a manutenção da linguagem são balizados pela demanda do ambiente e como não há regras formais a serem aprendidas, o processamento da linguagem ocorre por meio do ajuste gradual de conexões feitas pela extração das regularidades de uso da linguagem a partir de fatores estatísticos e probabilísticos presentes no input ao qual um falante é exposto. Assim, balizados pelo contexto de L2 dominante ou pelo constante contato com uma L2 em um contexto de L1 dominante, dada a recência e a frequência dessa língua, haverá alteração na robustez das redes neuronais responsáveis pela produção dos sons da L1, disparando o processo de atrito. 
Como podemos perceber, certamente, ainda há uma longa jornada para entendermos o fenômeno do atrito de L1; contudo, o paradigma conexionista, respeitando a complexidade inerente à linguagem, sobretudo pela previsão de uma representação linguística complexa e sensível ao uso efetivo da língua, parece-nos um possível norte a ser seguido. Esperamos, então, que este trabalho venha colaborar, mesmo que de maneira simples, para um melhor entendimento desse fenômeno. Desejamos, também, que esta leitura teórica do atrito tenha trazido à tona mais perguntas do que respostas, e que fomente essa área de estudo. Fica, então, nosso apelo e sugestão para futuras investidas.

\section{REFERÊNCIAS}

ALVES, U. K. Uma discussão conexionista sobre a explicitação de aspectos fonético-fonológicos da L2: dados de percepção e produção da plosiva labial aspirada do inglês. In: POERSCH, J; ROSSA, A. (org.). Processamento da Linguagem e Conexionismo. Santa Cruz do Sul: EDUNISC, 2007. p. 155-185.

BEST, C.; TYLER, M. Nonnative and second-language speech perception: commonalities and complementarities. In: BOHN, O.; MUNRO, M. Language Experience in Second Language Speech Learning: In honor of James Emil Flege. Amsterdam: John Benjamins, 2007. p. 13-34.

BONILHA, G. Aquisição fonológica do português brasileiro: uma abordagem conexionista da teoria da Otimidade. [Tese de Doutorado.] Programa de Pós-graduação em Letras. PUCRS, 2004.

BORGES, R., IAROSZ, K.; BATISTA, A.; CALDAS, I.; BORGES, F.; LAMEU, E. Sincronização de disparos em redes neuronais com plasticidade sináptica. Rev. Bras. Ensino Fís. São Paulo, vol.37 n. 2, abr./jun. 2015.

CASTRO, J. A influência do conteúdo emocional na recordação de textos: uma abordagem conexionista. In: POERSCH, M; ROSSA, A (eds.). Processamento da linguagem e conexionismo. Santa Cruz do Sul: EDUNISC, 2007, p. 22-60. 
CHOMSKY, N. Syntactic Structures. Cambridge, Massachusetts: MIT Press, 1957.

COHEN, G. The VOT dimension: a bi-directional experiment with English and Brazilian-Portuguese stops. 2004. [Dissertação de Mestrado em Letras.] Florianópolis: Universidade Federal de Santa Catarina, 2004. 70fls.

COOK, V. The Changing L1 in the L2 User's Mind. Effects of the Second Language on the First. Clevedon: Multilingual Matters, 2006.

CRYSTAL, D. Towards a philosophy of language diversity. Trabalho apresentado em 'Dialogue of Cultures', Reykjavik, 14 de abril 2005.

DE BOT, K. Dynamic Systems Theory, Lifespan Development and Language Attrition. In: KÖPKE, B.; SCHMID, M.; KEIJER, M.; DOSTERT. Language Attrition. Theoretical Perspectives. Amsterdam: John Benjamins. 33, 2007. p. 53-68.

ECKE, P. Language attrition and theories of forgetting: A cross-disciplinary review. International Journal of Bilingualism, 8 (3), p. 321-354, 2004.

FINGER, I. A abordagem conexionista de aquisição da linguagem. In: FINGER, I; QUADROS, R (eds.). Teorias de aquisição da linguagem. Florianópolis: Editora da UFSC, 2008, p. 127-144.

FLEGE, J. E. The production of "new" and "similar" phones in a foreign language: Evidence for the effect of equivalence classification. Journal of Phonetics, n. 15, p. 47-65, 1987.

Second language speech learning: Theory, findings, and problems. In: STRANGE, W. (e.), Speech perception and language experience: Issues in cross-language research, Baltimore: York Press, 1995. p. 233-277.

Interactions between the native and second-language phonetic systems. In: BURMEISTER, P.; PISKE, T; ROHDE, A. (es.). An integrated view of language development: Papers in honor of Henning Wode Trier. Germany: Wissenschaftlicher Verlag, 2002. p. 217-244. 
FOOTNICK, R.; PALLIER, C.; PRIEUR, N. A lost language: recovery is triggered by hypnosis. Trabalho apresentado no Second International Conference on First Language Attrition. Amsterdam: 17-20 ago. 2005.

GASSER, M. Connectionism and universals of second language acquisition. Studies in Second language acquisition, 12, p. 179-199, 1990. Disponível em <http://www.cs.indiana.edu/ gasser/ Research/pubs.html.>. Acesso em: jun. 2016.

GORAL, M. First language decline in healthy aging: Implications for attrition in bilingualism. Journal of Neurolinguistics, 17 (1), p. 31-52, 2004.

KÖPKE, B.; SCHMID, M. Language Attrition In: SCHMID, M.; KÖPKE, B; KEIJZER, M.; WEILEMAR, L. (eds.). Language Attrition: Interdisciplinary Perspectives on Methodological Issues. Amsterdam: John Benjamins, 2004. p. 1-43.

KUPSKE, F. Efeitos do contato entre categorias fonéticas distintas em contextos de imigração: uma revisão sobre o atrito de língua materna. Gragoatá, Niterói, v. 22, n. 42, p. 85-106, jan./ abr. 2017. Disponível em: <http://www.gragoata.uff.br/index. php/gragoata/article/view/903/634>. Acesso em: abr. 2018.

Imigração, atrito e complexidade: a produção das oclusivas surdas iniciais do inglês e do português por sul-brasileiros residentes em Londres. [Tese de Doutorado em Letras.] Porto Alegre: UFRGS, 2016.

. Aquisição da linguagem à luz de um paradigma teórico de cognição. Littera. v.2, n.4, p. 174-190, 2011.

LAMBERT, R. Setting the agenda. In: LAMBERT, R; FREED, F. The loss of language skills. Rowley, MA: Newbury House, 1982.

LAMBERT, R. FREED, F. The loss of language skills. Rowley, MA: Newbury House, 1982.

LIZARDI, L. A connectionist approach to language acquisition, 2000. Disponível em <www.eric.ed.gov/ERICWebPortal/ contentdelivery/servlet/ERICServlet?accno=ED4 3944>. Acesso em: 12 fev. 2011. 
LORD, G. Second language acquisition and first language phonological modification. In: GARAVITO, J. (org.). Selected proceedings of the 10th hispanic linguistics symposium. Somerville: Cascadilla Proceedings Project, 2008. p. 184-193.

MAJOR, R. C. First language attrition in foreign accent perception. Journal of Bilingualism,14 (2), p. 163-183, 2010.

MEDLER, D. A brief history of connectionism. Neural Computing Surveys, v.1, n.2, p. 18-72, 1998. Disponível em http://citeseerx. ist.psu.edu/viewdoc/summary?doi=10.1.1.97.9853. Acesso em: 14 fev. 2015.

OPITZ, C. First language Attrition and Second Language Acquisition in a Second-Language Environment. [Tese de Doutorado.] Dublin: Trinity College, 2011. 341fls.

POERSCH, M. A new paradigm for learning language: Connectionist artificial intelligence. Linguagem $\mathcal{E}$ ensino, v.8, n. 1, p. 161-183, 2005. Disponível em <http://rle.ucpel.thce.br/ php/edicoes/v8n1/marcelino.pdf.> . Acesso em 30 mar. 2011.

Simulações conexionistas: a inteligência artificial moderna. In: ; ROSSA, A (eds.). Processamento da linguagem e conexionismo. Santa Cruz do Sul: EDUNISC, 2007.

RUMELHART, D; MCCLELLAND, J. Parallel distributed Processing: Explorations in the microstructure of cognition. Cambridge, MA, USA: MIT Press, 1986.

SANCIER. M. L.; FOWLER, C. A. Gestural drift in a bilingual speaker of Brazilian Portuguese and English. Journal of Phonetics, 27(4), p. 421-436, 1997.

SCHMID, M. S. The Role of L1 Use for L1 Attrition. In: KÖPKE, B.; SCHMID, M. S.; KEIJZER, M.; DOSTERT, S. (eds.). Language Attrition: Theoretical Perspectives. Amsterdam; Philadelphia: Benjamins, 2007. (Studies in Bilingualism, 33)

Languages at Play: The Relevance of L1 Attrition to the Study of Bilingualism. Bilingualism: Language and Cognition, 13 (01), p. 1-7, 2010. 
SCHMID, M. S. Language Attrition. Cambridge: Cambridge University Press, 2011.

SCHERESCHEWSLY, L.; ALVES, U. K.; KUPSKE, F. First language attrition: the effects of English (L2) on brazilian portuguese VOT patterns in an 11-dominant environment. Letrônica. Porto Alegre, v. 10. n.2, p. 700-716, 2017.

TORIBIO, A; BULLOCK, B.; BOTERO, C.; DAVIES, K. Perseverative phonetic effects in bilingual code-switching. In: GESS, R. S.; RUBIN, E. J. (eds.). Theoretical and experimental approaches to Romance linguistics. Salt Lake City: John Benjamins, 2005. p. 291-306.

ZIMMER, M.; ALVES, U. A instrução explícita na aprendizagem da L2: uma abordagem conexionista. Nonada, Porto Alegre-RS, v. 8, p. 221-232, 2005. 


\section{Abstract}

\section{A cognitive reading of the process of non-pathological first language loss}

The process of non-pathological loss of a mother tongue, here taken as L1 attrition, is a phenomenon that has only recently been investigated more thoroughly in the linguistic studies. Because of this theoretical gap, then, we seek, in this work, to interpret L1 attrition in the light of a paradigm of cognition, more specifically the connectionist paradigm, an approach not yet made in the literature of the area. In our investigation, we can see that the connectionist paradigm, sensitive to the inherent dynamicity of language, especially by predicting a complex linguistic representation and by considering the effective use of language as the trigger for language development, is a theoretical model capable of explaining language attrition.

Keywords: Language Acquisition; Language Attrition; Connectionism. 